\title{
Dual Effect of Nitrate Therapy for Cyclosporine-Induced Hypertension on Vascular and Platelet Morphofunctional Markers; An Animal Model
}

\author{
F. Reis, E. Teixeira de Lemos, L. Almeida, B. Parada, A.P. Garrido, P. Rocha-Pereira, A. Santos-Silva, \\ J. Santos-Dias, A. Dinis, A. Figueiredo, C. Costa-Almeida, A. Mota, and F. Teixeira
}

\begin{abstract}
The present study sought to evaluate the prevention and reversion effects of isosorbide5-mononitrate (Is-5-Mn) on the development of hypertension (HT) and on the underlying vascular and platelet morphofunctional disturbances, using an animal model of cyclosporine (CsA)-induced HT. The following rat groups $(\mathrm{n}=8)$ were tested: $(1)$ a control group (orange juice, for 7 weeks); (2) the CsA group ( $5 \mathrm{mg} / \mathrm{kg} / \mathrm{d}$ for 7 weeks); (3) the Is-5-Mn group $(150 \mathrm{mg} / \mathrm{kg} / \mathrm{d}$, twice a day for 7 weeks); (4) the prevention group (Is-5-Mn + CsA) treated for 2 weeks with Is-5-Mn only and thereafter with both drugs for 7 weeks; (5) the curative group (CsA + Is-5-Mn) beginning 7 weeks after CsA and following thereafter with both drugs for 5 weeks. Blood pressure, lipid profile, vascular lesion, platelet aggregation and morphology, and platelet thromboxane $\mathrm{A}_{2}$ /vascular prostacyclin equilibrium were evaluated. Is-5-Mn + CsA therapy prevented (systolic blood pressure [SBP]: $114.3 \pm 1.9 \mathrm{~mm} \mathrm{Hg}, P<.001$; diastolic blood pressure [DBP]: $97.0 \pm 3.3 \mathrm{~mm} \mathrm{Hg}, P<.001)$ the CsA-induced HT (SBP: $146.2 \pm 4.5 \mathrm{~mm} \mathrm{Hg}, P<.001$; DBP: $124.9 \pm 4.5 \mathrm{~mm} \mathrm{Hg}, P<$ .001 vs control: SBP: $111.6 \pm 0.7 \mathrm{~mm} \mathrm{Hg}$; DBP: $94.6 \pm 1.0 \mathrm{~mm} \mathrm{Hg}$ ), as well as the vascular lesion and the platelet morphofunctional disturbances. The curative group did not show attenuated CsA-induced BP increase; it showed further enhancement of the HT effect (SBP: $159.7 \pm 5.5 \mathrm{~mm} \mathrm{Hg}, P<.05$; DBP: $132.8 \pm 2.8 \mathrm{~mm} \mathrm{Hg}$ ), as well as worsened vascular lesions and platelet function, namely a disruption in the $\mathrm{TXA}_{2} / \mathrm{PGI}_{2}$ equilibrium. Our data suggested that Is-5-Mn therapy may be a valid choice to prevent the morphofunctional changes associated with CsA-induced HT, when used as a preventive therapy. A careful evaluation of the impact of nitrate therapy should be considered, particularly the negative effect on cardiovascular hemodynamics, when considering its use after previous CsA disturbances have been established.
\end{abstract}

$\mathrm{D}$ ESPITE THE INTRODUCTION of new immunosuppressive drugs in the therapeutic regimens for prevention of allograft rejection in solid organ transplantation, the use of calcineurin inhibitors is recommended to

From the Institute of Pharmacology and Experimental Therapeutics (F.R., E.T.L., L.A., B.P., A.P.G., F.T.) and Institute of Physiology (C.C.-A.), Faculty of Medicine, Coimbra University, Coimbra, Portugal; Department of Urology and Renal Transplantation (B.P., A.F., A.M.), Coimbra University Hospital, Coimbra, Portugal; Chemistry Department (P.R.-P.), Beira Interior University, Covilhã, Portugal; Biochemistry Service (A.S.-S.), Faculty of Pharmacy, Porto University, Porto, Portugal; Molecular and Cellular Biology Institute (P.R.-P., A.S.-S.), Porto University, prevent both acute and chronic rejection. Cyclosporine (CsA) is still, after more than 20 years of great success, one of the most relevant immunosuppressive compounds. ${ }^{1}$ However, CsA therapy has been associated with serious

Porto, Portugal; Electron Microscopy Laboratory (J.S.-D., A.D.), Botanic Department, Faculty of Science and Technology, Coimbra University, Coimbra, Portugal.

Address reprint requests to Prof Frederico Teixeira, Therapeutics Unit, Institute of Pharmacology and Experimental Therapeutics, Faculty of Medicine, Coimbra University, 3004-504 Coimbra, Portugal. E-mail: fredit@ci.uc.pt 
side effects, particularly nephrotoxicity and hypertension (HT) ${ }^{2-4}$ While cardiovascular complications remain the main cause of posttransplantation mortality, ${ }^{5-7}$ the pathophysiology of CsA-induced de novo HT is not yet fully understood. Several mechanisms have been proposed by the research community. The most popular suggestion is increased systemic reactivity, which includes both augmented vasoconstrictor potential and decreased vasorelaxation. ${ }^{8,9}$ During the last years several experimental and clinical studies, including some from our institute, have indicated a cardiovascular dysfunction in nitric oxide (NO) production as one important cause for the reduced relaxation leading to vascular hyperreactivity and increased peripheral resistance. ${ }^{10,11} \mathrm{NO}$ is the main endotheliumderived relaxing factor. Through its conversion to cyclic guanosine-3', 5'-monophosphate (cGMP), it exerts vasodilatation, inhibition of vascular smooth muscle cell (VSMC) growth, and platelet inactivation, thus playing a pivotal role in cardiovascular physiology and pathophysiology, namely, arterial HT, atherosclerosis, and thrombosis. ${ }^{12,13}$ NO supplementation might, therefore, shown a positive role on CsA-induced vasomotor disequilibrium.

We and other groups have previously shown that an L-arginine complement, the natural NO synthase (NOS) substrate, despite normalizing the CsA-induced vascular and platelet NO/cGMP impairment, did not fully prevent HT development. ${ }^{14,15}$ Nitro-compounds might produce more effective effects because of their particular NO donor properties. Organic nitrates, the first molecules in which vasorelaxation characteristics were recognized, are the most well-known substances concerning those effects. They are commonly used for several cardiovascular disorders, including angina pectoris. ${ }^{16,17}$ They might also have a beneficial role in the vascular dysfunction associated with HT. This experimental study in rats sought to evaluate the effect of an organic nitrate, isosorbide-5-mononitrate (Is-5-Mn), on the prevention or reversion of CsA-induced HT, and on the underlying vascular and platelet morphofunctional disturbances.

\section{METHODS}

Male Wistar rats (280-300 g; Charles River Laboratories Inc, Barcelona, Spain) were maintained in an air conditioned room, subjected to 12-hour dark/light cycles, given standard laboratory rat chow (IPM-R20, Letica, Barcelona, Spain), and allowed free access to tap water. Animal experiments were conducted according to the European Communities Council Directives on Animal Care. The rats were divided into 5 groups (each with 8 rats) that treatment upon oral control group-only orange juice for 7 weeks; CsA group $-5 \mathrm{mg} / \mathrm{kg}$ body weight (BW)/d CsA (Sandimmune Neoral, Novartis Farma, Lisbon, Portugal), dissolved in orange juice, for 7 weeks; Is-5-Mn group-150 mg/kg BW/d, twice a-day, Is-5-Mn (Monopront, Ferraz-Lynce SA, Lisbon, Portugal) for 7 weeks; preventive group (Is-5-Mn + CsA) $-150 \mathrm{mg} / \mathrm{kg} / \mathrm{d}$, twice a day, Is-5-Mn for 2 weeks and the same dose of Is-5-Mn + CsA (5 $\mathrm{mg} / \mathrm{kg} / \mathrm{d}$ ) for an additional period of 7 weeks; curative/regressive group (CsA + Is-5-Mn) - $5 \mathrm{mg} / \mathrm{kg} / \mathrm{d}$ CsA for 7 weeks and the same dose of CsA $+150 \mathrm{mg} / \mathrm{kg} / \mathrm{d}$, twice a day, Is-5-Mn for an additional period of 5 weeks. All administrations were performed via esophageal cannulae at about the same hour of the day, 17:00 hours for control and CsA-treated rats. In order to have a daily nitrate-low/ free period of about 4 to 5 hours to overcome the hypothetical organic nitrate tolerance. Is-5-Mn twice a day administration was made asymmetrically at 10:00 and 17:00 hours. All determinations were performed at the end of the scheduled treatments.

Systolic (SBP) and diastolic blood pressures (DBP) were obtained using a tail-cuff sphygmomanometer LE 5001 (Letica, Barcelona, Spain), and appropriate contention cages for the rats. Blood pressure values were registered by the same person, in a similar peaceful environment, between 14:00 and 18:00 hours; the mean values were obtained by averaging 8 to 10 measurements.

At the end of the treatments the rats were administrated intraperitoneal anesthesia with a $2 \mathrm{mg} / \mathrm{kg}$ BW of a 2:1 (v:v) 50 $\mathrm{mg} / \mathrm{mL}$ ketamine (Ketalar, Parke-Davis, Laboratórios Pfeizer, Lda, Seixal, Portugal) solution in $2.5 \%$ chlorpromazine (Largactil, Rhône-Poulenc Rorer, Laboratórios Vitória, Amadora, Portugal), prior to sacrifice by cervical dislocation. Blood was withdrawn from the jugular vein by venipuncture, and collected into tubes with and without anticoagulant. The anticoagulants were heparin and a solution $(-0.1 \mathrm{~mL} / \mathrm{mL}$ blood) of acid citrate-dextrose containing citric acid $(71 \mathrm{mmol} / \mathrm{L})$, sodium citrate $(85 \mathrm{mmol} / \mathrm{L})$, and D-glucose $(111 \mathrm{mmol} / \mathrm{L})$. Blood was centrifuged $\left(160 \mathrm{~g}\right.$ for 10 minutes at $\left.20^{\circ} \mathrm{C}\right)$ to obtain the platelet rich plasma (PRP), which was then centrifuged $\left(730 \mathrm{~g}\right.$ for 10 minutes at $20^{\circ} \mathrm{C}$ ) to obtain the platelet pellet and the platelet poor plasma (PPP). To perform vascular tissue studies, the aorta was immediately removed and placed in ice-cold Krebs' buffer, carefully cleaned of adherent fat and connective tissue, and cut in segments, with special care to preserve the integrity of the endothelial layer.

Plasma total cholesterol (T-Chol), high-density lipoprotein cholesterol (HDL-Chol), low-density lipoprotein cholesterol (LDLChol), and triglycerides (TGs) were analyzed on a Hitachi 717

Table 1. Blood Pressure and Lipid Profile

\begin{tabular}{lccccc}
\hline & Control & CsA & Is-5-Mn & Is-5-Mn + CsA & CsA + Is-5-Mn \\
\hline Blood pressure (mm Hg) & & & & & \\
$\quad$ Systolic & $114.9 \pm 3.1$ & $146.2 \pm 4.5^{\star \star \star}$ & $116.8 \pm 2.4$ & $114.3 \pm 1.9^{\dagger \dagger \dagger}$ & $159.7 \pm 5.5^{\dagger}$ \\
$\quad$ Diastolic & $99.1 \pm 1.8$ & $124.9 \pm 4.5^{\star \star \star}$ & $104.1 \pm 2.6$ & $97.0 \pm 3.3^{\dagger+\dagger}$ & $132.8 \pm 2.8$ \\
Lipid profile & & & & \\
$\quad$ T-Chol (mmol/L) & $1.31 \pm 0.10$ & $1.62 \pm 0.09$ & $1.65 \pm 0.24$ & $1.53 \pm 0.09$ & $2.20 \pm 0.24^{\dagger}$ \\
TGs (mmol/L) & $1.13 \pm 0.06$ & $1.94 \pm 0.31^{\star \star}$ & $1.18 \pm 0.32$ & $1.33 \pm 0.15^{\dagger}$ & $1.20 \pm 0.12^{\dagger \dagger}$ \\
HDL-Chol (mmol/L) & $0.89 \pm 0.03$ & $0.98 \pm 0.04$ & $1.10 \pm 0.14$ & $0.95 \pm 0.07$ & $1.15 \pm 0.06^{\dagger}$ \\
LDL-Chol (mmol/L) & $0.10 \pm 0.01$ & $0.22 \pm 0.03^{\star}$ & $0.09 \pm 0.01$ & $0.10 \pm 0.01^{\dagger}$ & $0.22 \pm 0.06$ \\
\hline
\end{tabular}

Data are expressed as means \pm SEM of 8 separate values (rats). Significant differences between groups are expressed: ${ }^{\star} P<.05$, ${ }^{\star \star} P<.01$, and ${ }^{\star \star \star} P<.001$ vs the control group; ${ }^{\dagger} P<.05,{ }^{\dagger+} P<.01$, and ${ }^{\dagger+} P<.001$ vs the CsA group. 
analyzer (Roche Diagnostics). T-Chol reagents and TG kits were obtained from bioMérieux sa (Lyon, France); HDL-c Plus and LDL-c Plus tests, from F. Hoffmann-La Roche Ltd (Roche Diagnostics division, Basel, Switzerland).

To perform the morphohistological studies, the platelet pellets from the 5 rat groups, as well as the aortic segments, were fixed with glutaraldehyde $(2.5 \%$ in phosphate buffer $0.025 \mathrm{~mol} / \mathrm{L}, \mathrm{pH}$ 6.8) for 1 hour. After several washings in the same buffer, postfixation was performed for 1 hour with osmium tetroxide (Sigma Chemicals, St Louis, Mo, USA), $1 \%$ in phosphate buffer $0.05 \mathrm{~mol} / \mathrm{L}$ ( $\mathrm{pH}$ 6.8). After a further washing, the platelets were preembedded in agar (2\% in distilled water) which was cut into $1 \mathrm{~mm}$ pieces. Both platelet and aorta samples were dehydrated first through resuspension in increasing concentrations of alcohol (20\%-100\%) for at least 15 minutes for each concentration, and, finally, with increasing concentrations of propylene oxide in alcohol. The final embedding in a low-viscosity resin EPON 812 (TAAB, Berkshire, UK) was performed by progressively increasing the concentration of resin in propylene oxide to $100 \%$. After polymerization $\left(60^{\circ} \mathrm{C}\right.$ for a day), the blocks were cut on an LKB ultramicrotome, using a diamond knife. Ultrathin sections were placed on uncoated copper grids for observation under a JEM-100SX, JEOL electron microscope (TEM), after uranyl/lead citrate staining.

Whole blood platelet aggregation was monitored by measuring electric impedance using a Chrono-log aggregometer (Chrono-Log Corp, Havertown, Pa, USA). Fresh heparinized whole blood $(0.5$ $\mathrm{mL})$ and $0.9 \% \mathrm{NaCl}(0.5 \mathrm{~mL})$ mixed using a magnetic stirrer were allowed to balance at $37^{\circ} \mathrm{C}$ for 5 minutes before adding the agonists, adenoside diphosphate (ADP: $1.0 \mu \mathrm{mol} / \mathrm{L}$ ) and collagen type I, equine origin; $5 \mu \mathrm{g} / \mathrm{mL}$; (both from Chrono Log-Corp). Aggregation values were expressed in Ohms.

Platelet thromboxane $\mathrm{A}_{2}\left(\mathrm{TXA}_{2}\right)$ levels were assessed through the quantification of its stable end product, the inactive $\mathrm{TXB}_{2}$. To assess arachidonic acid (AA)-induced platelet $\mathrm{TXB}_{2}$ production, platelets were counted and, afterward, $0.1 \mathrm{mmol} / \mathrm{L}$ acetylsalicylic acid (AAS) was added to the tubes containing the PRP samples to block cyclooxygenase (COX) activity, and $120 \mu \mathrm{mol} / \mathrm{L}$ of aracidonic acid (AA). After 5 minutes incubation at $37^{\circ} \mathrm{C}$, the reactions were stopped by adding indomethacin $(100 \mu \mathrm{mol} / \mathrm{L})$ and placing the tubes in ice for 1 to 2 minutes. The supernate containing $\mathrm{TXB}_{2}$ was obtained after centrifugation $\left(1200 \mathrm{~g} / 10 \mathrm{~min} / 4^{\circ} \mathrm{C}\right)$ and further extracted with hexane and chloroform, according to the immunoassay kit instructions. The amount of $\mathrm{TXB}_{2}$ released by the platelets was assessed using an enzymatic immunoassay (Amersham Biosciences Biotech UK Lt, Buckinghamshire, UK), calculating the percentage of iodinated $\mathrm{TXB}_{2}$ bound to a protein precipitate. All assays were performed in duplicate. Values were expressed in $\mathrm{pg} / 10^{9} \mathrm{plat} / \mathrm{mL}$.

The vascular prostacyclin $\left(\mathrm{PGI}_{2}\right)$ production in the thoracic aorta, which was removed and cleaned as described above, was assessed by measuring its stable end product, the inactive 6-keto$\mathrm{PGF}_{1 \alpha}$. The segments were incubated for 5 minutes at $37^{\circ} \mathrm{C}$ with 50 $\mu \mathrm{mol} / \mathrm{L}$ of $\mathrm{AA}$ in $1 \mathrm{~mL}$ of buffer $(\mathrm{pH} 8.3)$ containing $\mathrm{KCl}(3.9$ $\mathrm{mmol} / \mathrm{L}), \mathrm{NaCl}(105 \mathrm{mmol} / \mathrm{L}), \mathrm{NaHCO}_{3}(20 \mathrm{mmol} / \mathrm{L}), \mathrm{Na}_{2} \mathrm{SO}_{4}(1.7$ $\mathrm{mmol} / \mathrm{L})$, sodium citrate $(18.9 \mathrm{mmol} / \mathrm{L})$, glucose $(2.7 \mathrm{mmol} / \mathrm{L})$, and Tris $(50 \mathrm{mmol} / \mathrm{L})$. The tissue segment was removed and 100 $\mu \mathrm{mol} / \mathrm{L}$ of indomethacin added to prevent degradation. Aortic 6-keto-PGF ${ }_{1 \alpha}$ was measured using an enzymatic immunoassay kit (R\&D Systems, Inc, Abingdon, UK). All assays were performed in duplicate. Values were expressed in $\mathrm{pg} / \mathrm{mg}$ tissue wet weight.

Results are expressed as mean values \pm standard errors of the mean (SEM) of $n$ experiments. Differences between groups were tested by performing ANOVA, followed by the Fisher protected least significant difference (PLSD) test, using Statview 4.53 software from Abacus Concepts Inc (Berkeley, Calif, USA). Differences were considered significant at $P<.05$. The monotherapy groups of CsA and Is-5-Mn were compared with the controls and the Is-5-Mn + CsA and CsA + Is-5-Mn groups with the CsA one.

\section{RESULTS}

To evaluate blood pressures at the initial time (week 0), a group of 30 rats was chosen at random from the total rats,

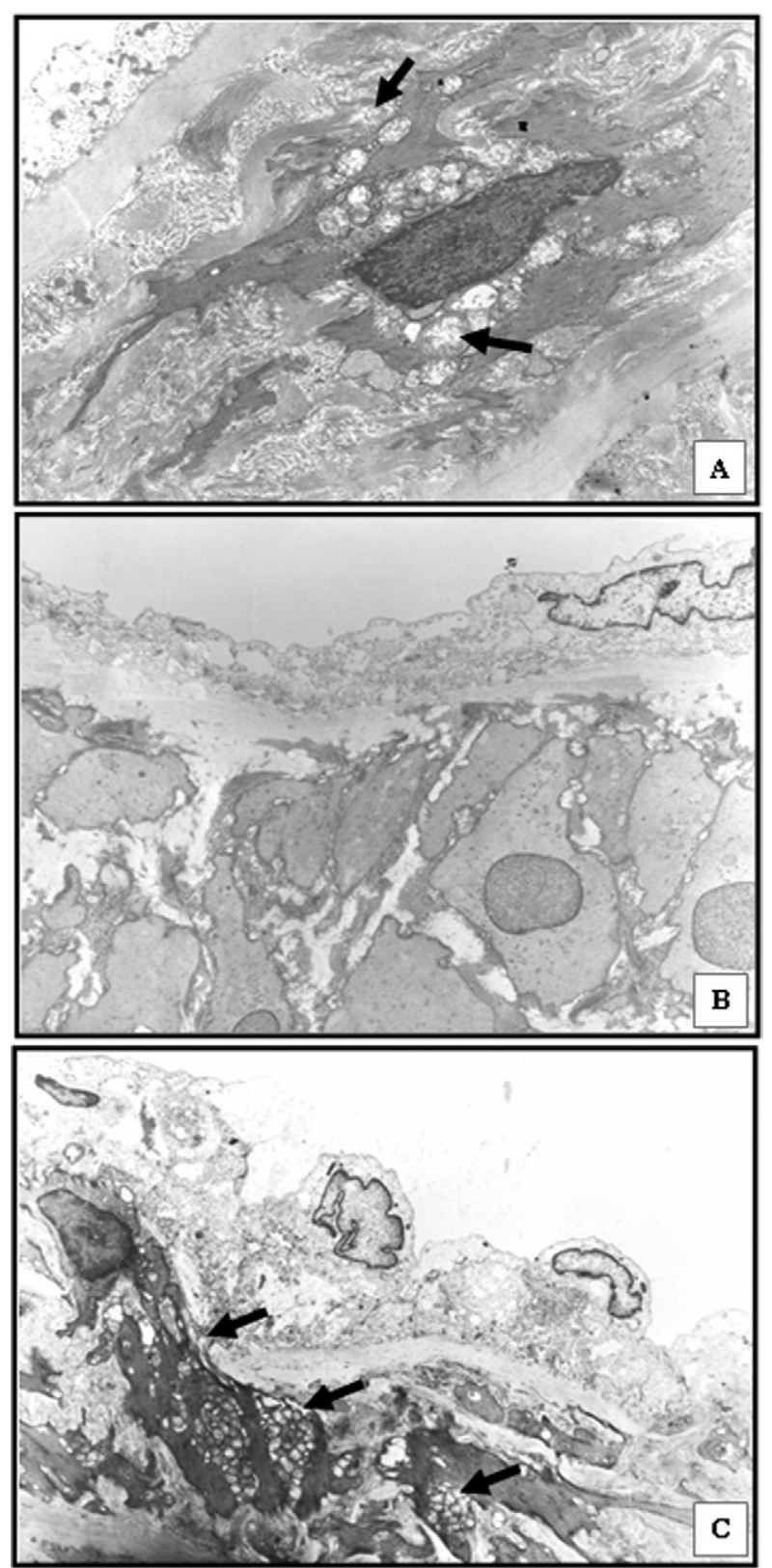

Fig 1. Electron microscopic histopathology pictures of aorta segments from the CsA (A), the Is-5-Mn + CsA (B), and the CsA + Is-5-Mn (C) rats, at the end of each treatment (original magnification $\times 3500$ ). 
Table 2. Whole-Blood Platelet Aggregation and Thromboxane $A_{2} /$ Prostaglandin $I_{2}$ Equilibrium

\begin{tabular}{|c|c|c|c|c|c|}
\hline & Control & CsA & Is-5-Mn & Is-5-Mn + CsA & $\mathrm{CsA}+\mathrm{Is}-5-\mathrm{Mn}$ \\
\hline \multicolumn{6}{|l|}{ Platelet aggregation (Ohm) } \\
\hline ADP, $1 \mu \mathrm{mol} / \mathrm{L}$ & $10.4 \pm 1.3$ & $18.0 \pm 1.5^{\star \star \star}$ & $14.5 \pm 1.6$ & $14.8 \pm 1.5$ & $17.0 \pm 0.9$ \\
\hline Collagen, $5 \mu \mathrm{g} / \mathrm{mL}$ & $17.4 \pm 1.1$ & $22.0 \pm 1.5^{*}$ & $18.0 \pm 1.5$ & $17.92 \pm 1.5^{\dagger}$ & $21.4 \pm 0.9$ \\
\hline \multicolumn{6}{|l|}{$\mathrm{TXA}_{2} / \mathrm{PGI}_{2}$ equilibrium } \\
\hline Platelet $\mathrm{TXB}_{2}\left(\mathrm{pg} / 10^{9} \mathrm{plat} / \mathrm{mL}\right)$ & $1.0 \pm 0.2$ & $2.18 \pm 0.2$ & $1.1 \pm 0.6$ & $2.83 \pm 0.68$ & $9.5 \pm 1.7^{\dagger+\dagger}$ \\
\hline Aortic 6-keto-PGF ${ }_{1 \alpha}(\mathrm{pg} / \mathrm{mg}$ tissue) & $483.7 \pm 87.4$ & $465.2 \pm 91.3$ & $235.7 \pm 39.6$ & $357.8 \pm 73.6$ & $440.9 \pm 107.8$ \\
\hline $\mathrm{TXB}_{2} / 6$-keto-PGF ${ }_{1 \alpha}$ ratio (ratio units) & $26.9 \pm 4.8$ & $61.4 \pm 8.0$ & $77.7 \pm 33.5$ & $77.0 \pm 20.9$ & $447.1 \pm 117.7^{\dagger \dagger \dagger}$ \\
\hline
\end{tabular}

Data are expresed as means \pm SEM of 8 separate values (rats). Significant differences between groups are expressed: ${ }^{\star} P<.05$, and ${ }^{\star \star \star} P<.001$ vs the control group; ${ }^{\dagger} P<.05$ and ${ }^{+\dagger} P<.001$ vs the CsA group.

showing values of $111.6 \pm 0.7$ and $94.6 \pm 1.0 \mathrm{~mm} \mathrm{Hg}$ for SBP and DBP, respectively. After 7 weeks of CsA treatment, there was a significant increase in SBP and DBP $(146.2 \pm 4.5$ and $124.9 \pm 4.5 \mathrm{~mm} \mathrm{Hg} ; P<.001)$ compared with the controls $(114.9 \pm 3.1$ and $99.1 \pm 1.8 \mathrm{~mm} \mathrm{Hg}$; (Table 1). In the rats treated only with Is-5-Mn, there were no significant differences in the values of BPs versus the control group. In the preventive Is-5-Mn group, the observed values were significantly lower than in the CsAtreated rats $(P<.001)$; they were similar to those of the control group. That is, the CsA-induced SBP and DBP rise was prevented by previous Is-5-Mn treatment (Table 1). In the CsA + Is-5-Mn group, the BPs (particularly SBP) were even higher than those of the CsA group (159.7 $\pm 5.5 \mathrm{~mm}$ $\mathrm{Hg}, P<.05$ and $132.8 \pm 2.8 \mathrm{~mm} \mathrm{Hg}$, respectively), showing no regression of the CsA-induced HT; actually, there was a worsening effect on BP (Table 1).

Concerning the lipid profile, when compared with the control rats CsA-treated rats showed increased levels of TGs $(P<.01)$ and LDL-Chol $(P<.05)$, and similar values of T-Chol and HDL-Chol (Table 1). Previous Is-5-Mn treatment (Is-5-Mn + CsA group) prevented the abovementioned effects, while treatment with both CsA and Is-5-Mn, after CsA administration (CsA + Is-5-Mn group) led to T-Chol levels even higher than those of the CsA group and to LDL-Chol values similar to those of the CsA-treated rats, demonstrating no reversion or attenuation; however, we observed a reduction in TGs and a rise in HDL-Chol (Table 1).

The pictures of vascular histopathology obtained by electron microscopic techniques showed vascular lesion profiles in the aortae of CsA-treated rats. The main changes were disorganization of the intimae and myointimae structures, particularly, the elastic fibers of the VSMCs, with some lipid accumulation, particularly in the extracellular spaces between the intimae layer and VSMCs (Fig 1A). In the preventive group (Is-5-Mn + CsA), the CsA effects were prevented, since we did not observe signals of vascular lesions (Fig 1B), as were seen in the group treated only with nitrate (data not shown). In contrast, the curative group (CsA + Is-5-Mn) showed accentuated vascular lesion profiles with greater structural disorganization and intense accumulation of lipid vesicles, not only in the intimae but also in the myointimal cells (Fig 1C).
ADP-induced whole-blood platelet aggregation was significantly greater in the CsA compared with the control group $P<.001$; (Table 2 ). The other groups showed values similar to those of the CsA group. The Is-5-Mn group, as well as the preventive group (Is-5-Mn + CsA), showed similar ADP-induced platelet aggregation. Moreover, the values in these groups were higher than those of the control group, but never reached those in the CsA group. However, the curative group (CsA + Is-5-Mn) showed a value similar to that obtained in the CsA group (Table 2). Platelet aggregation in whole blood induced by collagen displayed the same pattern of changes: significantly higher values in the CsA $(P<.05)$ compared with the control group; higher values in the Is-5-Mn and in the Is-5-Mn + CsA $(P<.05)$ groups compared with the controls, but significantly lower than CsA. The $21.4 \pm 0.9$ ohm value observed in the CsA + Is-5-Mn group, was similar to the CsA one (Table 2), demonstrating no reversion or attenuation of the CsAinduced platelet hyperaggregation.

The platelet morphology seen by electron microscopy was consistent with the whole-blood platelet aggregation results, since $\mathrm{CsA}$-induced platelet activation signals were evident (Fig 2A), as well as the prevention in the Is-5-Mn + CsA group (Fig 2B) and maintenance in the curative CsA + Is-5-Mn group (Fig 2C).

Although the AA-induced platelet $\mathrm{TXB}_{2}$ production was higher in the CsA-treated group, it did not reach statistical significance compared with the controls (Table 2). Similar values were obtained in the Is-5-Mn as well as in the Is-5-Mn + CsA groups compared with the CsA-alone group. However, in the curative group (CsA + Is-5-Mn), there was a significant increase in platelet $\mathrm{TXB}_{2}$ production $\left(9.54 \pm 1.69 \mathrm{pg} / 10^{9} \mathrm{plat} / \mathrm{mL} ; P<.001\right)$ compared with the CsA group or other Is-5-Mn-treated groups (Table 2). The aortic 6-keto-PGF ${ }_{1 \alpha}$ production under AA-inducing conditions was identical in all groups; only a trend to lower values was observed in the Is-5-Mn and in the Is-5-Mn + CsA cohorts (Table 2). The $\mathrm{TXB}_{2} / 6-$ keto- $\mathrm{PGF}_{1 \alpha}$ ratio, which reflects the platelet $\mathrm{TXA}_{2}$ /aortic $\mathrm{PGI}_{2}$ equilibrium, showed disequilibrium in the CsA + Is-5-Mn group compared with all the other groups $(P<.001$ and $P<.01)$, which resulted from the greater production of the vasoconstrictor platelet $\mathrm{TXB}_{2}$ (Table 2). 

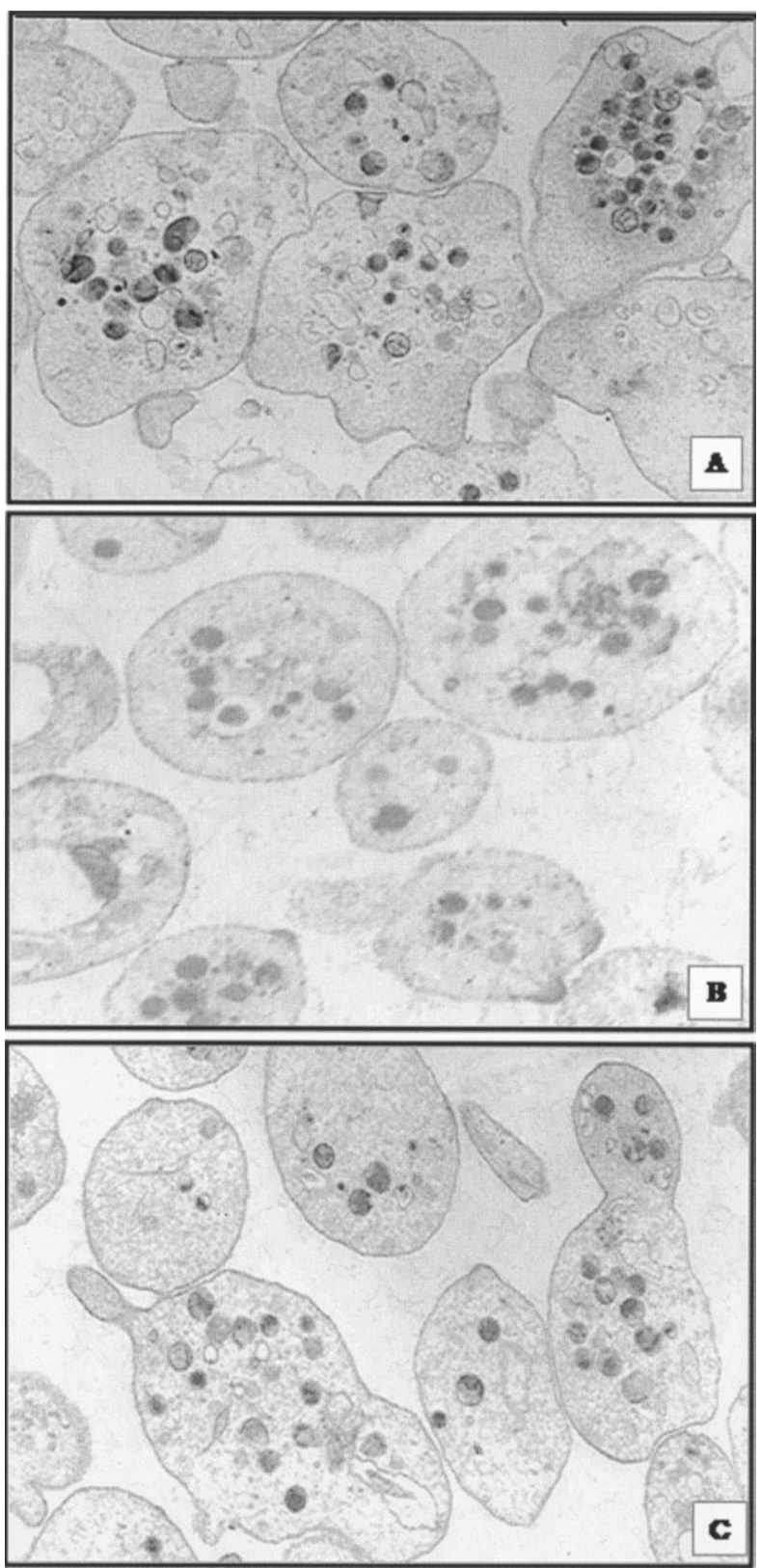

Fig 2. Electron microscopic morphology pictures of platelets from the control (A), the Is-5-Mn + CsA (B), and the CsA + Is-5-Mn (C) rats, at the end of each treatment (original magnification $\times 16,800$ ).

\section{DISCUSSION}

As previously reported by us as well as by other groups, this study confirmed the development of CsA-induced arterial HT. ${ }^{18,19}$ Concomitant Is-5-Mn and CsA treatments produced distinct effects on blood pressure. When Is-5-Mn was used prophylactically (Is-5-Mn + CsA group), HT was prevented, but when used as regressive/curative therapy (CsA + Is-5-Mn group) it was accentuated. Thus, organic nitrate might be an important therapy where used under the appropriate circumstances, prophylactically. However particular care is needed when the CsA effects are already established, because of the negative impact of nitrate at this time.

The distinct influence on CsA-induced HT development of 2 protocols for nitrate therapy supplementation, preventive or curative/regressive, also showed distinct interferences with several vascular and platelet morphofunctional indices. The hyperlipidemic profile observed in the CsA group (a significant rise in TGs and LDL-Chol) was prevented in the prophylactic, while in the curative group the changes were not reversed. Actually, total-Chol levels were even higher. A preventive effect was also observed for the vascular lesions associated with CsA treatment, as well as for the accentuated lipid accumulation in the VSMCs observed in the CsA + Is-5-Mn group. Both results agree, suggesting that reversion of the hyperlipidemic state may underlie the reduction in vascular lesions.

Platelet hyperaggregation in CsA-treated rats, which confirms previous results, ${ }^{20}$ was partially prevented, but not corrected, by Is-5-Mn. This pattern of platelet functionality was strengthened by the morphological data using electron microscopy, which confirmed the reduced platelet activation in the prophylactic nitrate group and the absence of a beneficial effect with curative Is-5-Mn therapy. Furthermore, the distinct behavior observed in the preventive versus curative nitrate treatment was also obvious when analyzing the $\mathrm{TXA}_{2} / \mathrm{PGI}_{2}$ balance. In fact, when used before CsA, Is-5-Mn had no negative influence on the content of those important vascular modulators, but when used after $\mathrm{CsA}$, the $\mathrm{TXA}_{2} / \mathrm{PGI}_{2}$ balance was disrupted toward an increase in the vasoconstrictor agent, enhancing the deleterious cardiovascular conditions associated with CsA treatment.

The striking differences between the effects of the 2 nitrate treatments on all parameters suggested an important influence of NO system dysfunction in CsA-induced vascular and platelet hyperreactivity underlying increased vascular resistance and HT. Therefore, it is likely that NO supplementation, through Is-5-Mn administration before CsA, supplies the vascular environment with an NO stock, preventing its further depletion by CsA and all resultant modifications. Our data suggested that NO depletion was one of the pivotal causes for the cardiovascular disturbances associated with CsA-induced HT. Therefore, it would be important to test the use of NO donors as therapy.

However, we must be aware of the negative interference of nitrate treatments when administered after CsA. A reasonable explanation for the deleterious effect is the formation or accumulation of oxygen and nitrogen reactive species, resulting from the higher NO produced by the nitrate. Therefore, under certain circumstances, NO may have deleterious effects, namely, when it is conjugated with superoxide anion. In this case, it may lead to the production of other reactive oxygen species (ROS), such as peroxynitrite, which have negative influences on several vascular and 
platelet mechanisms. ${ }^{21,22}$ The impaired $\mathrm{TXA}_{2} / \mathrm{PGI}_{2}$ balance and the platelet hyperaggregation state, together with the more atherogenic lipid profile observed in the CsA + Is-5-Mn group, may contribute to vascular and platelet vasoconstrictor imbalance, explaining the worsened effects of that treatment compared with CsA alone. In contrast, nitrate treatment given before the immunosuppresant prevented the rise in BP, lipids, vascular lesions, and platelet activation.

In conclusion, NO seems to play a key role in the cardiovascular modifications underlying CsA-induced HT. Furthermore, Is-5-Mn treatment could be a method to prevent not only the blood pressure rise but also the vascular and platelet pathophysiological modifications induced by CsA, when given before the changes induced by CsA are already established. However, careful evaluation of the impact of nitrate therapy must be considered, particularly its negative effect on cardiovascular hemodynamics, when used after previous establishment of CsA disturbances, which are probably due to the interferences of ROS. Two important consequences of the present work for clinical practice should be considered, if the studies described herein are further confirmed. One is the possibility of using preventive nitrate therapy when a transplantation is programmed, such as occurs with live donors. The second is that physicians who use nitrates to improve cardiac performance in patients already undergoing CsA therapy must be aware of an associated risk.

\section{ACKNOWLEDGMENTS}

This study had the kind collaboration of Novartis Farma (Lisbon, Portugal) which supplied the cyclosporine (Sandimmune Neoral) and of Ferraz-Lynce (Lisbon, Portugal) which supplied the isosorbide-5mononitrate (Monopront).

\section{REFERENCES}

1. Cortesini R: Cyclosporine-lessons from the first 20 years. Transplant Proc 36(2 suppl):158S, 2004

2. Vitko S, Viklicky O: Cyclosporine renal dysfunction. Transplant Proc 36(2 suppl):243S, 2004

3. Taler SJ, Textor SC, Canzanello VJ, et al: Cyclosporininduced hypertension: incidence, pathogenesis and management. Drug Saf 20:437, 1999

4. Textor SC, Taler SJ, Canzanello VJ, et al: Posttransplantation hypertension related to calcineurin inhibitors. Liver Transpl 6:521, 2000
5. Kokado Y, Takahara S, Kamoeka H, et al: Hypertension in renal transplant recipients and its effect on long-term renal allograft survival. Transplant Proc 28:1600, 1996

6. Cosio FG, Falhenhain ME, Pesavento TE, et al: Relationship between arterial hypertension and renal allograft survival in African-American patients. Am J Kidney Dis 29:419, 1997

7. Olyaei AJ, de Mattos AM, Bennett WM: A practical guide to the management of hypertension in renal transplant recipients. Drugs 58:1011, 1999

8. Cartier R, Dagenais F, Hollmann C, et al: Chronic exposure to cyclosporine affects endothelial and smooth muscle reactivity in the rat aorta. Ann Thorac Surg 58:789, 1994

9. Vaziri ND, Ni Z, Zhang YP, et al: Depressed renal and vascular nitric oxide synthase expression in cyclosporine-induced hypertension. Kidney Int 54:482, 1998

10. Santiago M, Reis F, Almeida L, et al: Impairment of vascular and platelet nitric oxide and $3^{\prime}, 5^{\prime}$ cyclic guanosine monophosphate content in cyclosporine A-induced hypertensive rats. Fund Clin Pharmacol 17:43, 2003

11. Oriji GK, Keiser HR: Role of nitric oxide in cyclosporine A-induced hypertension. Hypertension 32:849, 1998

12. Anderson TJ: Nitric oxide, atherosclerosis and the clinical relevance of endothelial dysfunction. Heart Fail Rev 8:71, 2003

13. Loscalzo J: Nitric oxide insufficiency, platelet activation, and arterial thrombosis. Circ Res 88:756, 2001

14. Reis F, Santiago M, Almeida L, et al: Isosorbide-5mononitrate and L-arginine effect on the cyclosporin-induced arterial hypertension and vascular nitric oxide impairment. In Tooke J, Shore A, Whatmore J (eds): The Microcirculation and Vascular Biology. Bologna, Italy Monduzzi Editore S.p.A.; 2002, p 257

15. Lassila M, Santisteban J, Finckenberg P, et al: Vascular changes in cyclosporine A-induced hypertension and nephrotoxicity in spontaneously hypertensive rats on high-sodium diet. J Physiol Pharmacol 52:21, 2001

16. Gunasekara NS, Noble S: Isosorbide 5-mononitrate. A review of a sustained-release formulation (Indur) in stable angina pectoris. Drugs 57:261, 1999

17. Parker JO: Angina pectoris: a review of current and emerging therapies. Am J Manag Care 10(11 suppl):S332, 2004

18. Reis F, Tavares P, Fontes-Ribeiro CA, et al: The peripheral serotonergic system and platelet aggregation in cyclosporin Ainduced hypertensive rats. Thromb Res 96:365, 1999

19. Martin A, Wong KS, Li M, et al: Cyclosporin hypertension in the Wistar rat: role of uninephrectomy. Clin Exp Pharmacol Physiol 21:287, 1994

20. Reis F, Tavares P, Rito LC, et al: Platelet activation is increased in cyclosporin A-induced hypertensive rats. J Cardiovasc Pharmacol 36:56, 2000

21. Channon KM, Guzik TJ: Mechanisms of superoxide production in human blood vessels: relationship to endothelial dysfunction, clinical and genetic risk factors. J Physiol Pharmacol 53:515, 2002

22. Brown AS, Moro MA, Masse JM, et al: Nitric oxidedependent and independent effects on human platelets treated with peroxynitrite. Cardiovasc Res 40:380, 1998 